\title{
309 逆問題的手法による子どもの転落事故の状況推定法
}

The estimating method of the situation of child's downfall accident by inverse problem solution

\author{
鈴木 孝侑 （東工大院）正 宮崎 祐介（金沢大） \\ 正 丸山 剛生（東工大）正 宇治橋 貞幸（東工大） \\ 正 持丸 正明 (産総研) 西田 佳史 (産総研) 河内 まき子(産総研)
}

\begin{abstract}
Takayuki SUZUKI, Tokyo Institute of Technology, 2-12-1 Oh-okayama, Meguro-ku, Tokyo Yusuke MIYAZAKI, Kanazawa University, Kakuma-machi, Kanazawa-shi, Ishikawa Takeo MARUYAMA, Sadayuki UJHASHI, Tokyo Institute of Technology Masaaki MOCHIMARU, National Institute of Advanced Industrial Science and Technology, 2-41-6, Aomi, Koto-ku, Tokyo Yoshifumi NISHIDA and Makiko KOUCHI, National Institute of Advanced Industrial Science and Technology
\end{abstract}

In this study, the method to infer the situation of child's downfall accident by computer simulation was constructed. In the simulation, child multi-body model based on real children's body dimensions and actual spiral stairs model were used. Objective function based on a fall point after the accident was determined and a response surface was constructed to estimate the relationship between the objective function and input variables of the simulation. The circumstances of pre-accident were inferred by using genetic algorithm. The method was applied to a real accident and the estimated situation approximately corresponded to the real accident. The method showed the possibility to estimate the accident circumstances in a real accident.

Key Words: Multibody Dynamics, Child's accident, Inverse problem solution, Safety Engineering

\section{A. 1 緒論}

子どもの行動範囲は成脣により急速に拡大し, 事故に遭遇 する頻度が増加する.不慮の事故は死因の第 1 位であるだけ でなく,死に至らずとも重傷を負うことも多く効果的な対策 が必要である. 現在, 子ども事故サーベイランスシステムに よる事故情報の収集が進められているが, 目撃証言の少なさ や曖昧さなどから，事故の結果の情報しか入手できない場合 が多く，原因特定が困難である．事故の発生過程及び原因の 特定のためには, 事故の結果からあり得る事故形態を推定寸 る手法が必要となる。本研究では, 発生頻度が高く, かつ受 傷程度が重くなる場合が多い転落事故について, 実測された 身体寸法に基づく子どものマルチボディモデルを用いて転 落事故シミェレーションを行い, 事故の結果の情報から事故 状況を推定するための手法の構築を目的とした。

\section{A. 2 逆問題的手法による転落事故の状況推定法の構築}

実事故として遊具の螺旋階段に打汀る転落事故孝取り上 げ,被害幼児を模擬した 5 歳児のマルチボディモデルおよび 螺旋階段モデルを構築した。これらを用いて転落直前の子ど もマルチボディモデルの姿勢による転落挙動の違いを比較 し,姿勢を考慮したシミュレーションが必要であることを示 した.

次に, 事故の結果の情報のひとつである子どもの転落位置 を用いて, 転落開始位置と転落方向を推定し，これらを基に した事故シミュレーションを行らことで,転落挙動を推定す る手法を構築した。この状況推定法の妥当性を検証するため
に, 一例の転落シミュレーションを例題として実施し、推定 された事故状況と実際を比較した。 その結果, 外部環境亡の 衝突が単純な転落では実際とほぼ同じ状況が推定でき, 複雑 な転落では衝突形態に違いがあるものの定性的に類似した 举動を推定できた。このことから, 本推定法は複雑な転落挙 動の推定には精度に課題が残るものの, 方法論梳妥当であり, 単純な転落挙動であれば十分に推定できることを示した.ま た，推定精度向上には，モデルの外形状や接触特性により詳 細なデータを用いるなどの改良が必要であることがわかっ た.

\section{A. 3 状況推定法の実事故への適用}

最後に, 実事故に対して状況推定法を適用し, 事故状況の 推定を試みた。転落值前の子どもマルチボディモデルの姿勢 を変えながら転落挙動推定したところ,その中に転落举動 の中に事故状況によく合致するものが含まれており，本研究 で構築した状況推定法は, 実事故においても事故状況を推定 できる可能性があることを示した。

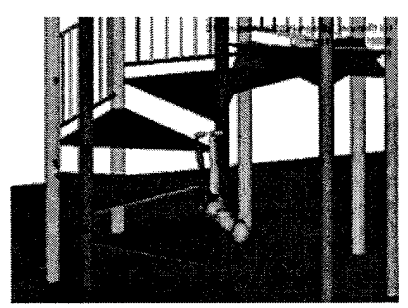

Fig. A.1 Child's downfall simulation of spiral stairs 


\section{1. 背景と目的}

子どもの行動範囲は成長により急速に拡大し, 事故に遭遇 する頻度が增加する.不慮の事故は死因の第 1 位 ${ }^{(1)} ゙$ あるだ けでなく、死に至らずとも重甥を負うことも多く効果的な対 策が必要である，現在，産総研や小児科医などにより子どむ 事故サーベイランスシステムによる事故情報の収集が進め られているが, 目撃証言の少なさや瞹眜さなどから, 事故の 結果の情報しか入手できない場合が多く，原因の特定が困難 な事例がある，事故の発生過程及び原因の特定のためには， 事故の結果からあり得る事故形態を推定する手法が必要々 なる、本研究では, 発生頻度が高く, かつ受傷程度が重くな る場合が多い転落事故 ${ }^{(2)}$ について, 実測された身体寸法に基 づく子どものマルチボディモデルを用いて転落事故シミュ レーションを行い, 事故の結果の情報から事故状沉を推定す るための手法の構築を目的とした.

\section{2. モデル構築と遊具事故シミュレーション}

はじめに, 渡辺ら ${ }^{(3)} の$ 手法を用い, Fig.2.1に示すような全 身の体節を棈円体近似した子どもマルチボディモデルを Fig.2.2のような流れで構築した。まず, Table 2.1 に示した 40 項目の子どもの身体寸法データから関節位置・体節形状 を定義した.本モデルは，全身を17体節16関節で構成する. 慣性特性は，横井ら ${ }^{(4)}$ のデー夕を基に算出された，接触特性 は HybridIIIダミーを基に貫入量と力の関係から定義した。 関節特性は回転角とモーメントの関係でモデル化し Yang ${ }^{(5)}$ らのデータを基に定義した. 用いた接触特性および関節特性 の一部を Fig.2.3，Fig.2.4にそれぞれ示す.

次に，外部環境モデルとして，実際に事故があった螺旋階 段のモデルを CAD データから構築した. Fig. 2.5 に螺旋階段 モデルを示す.

これらのモデルを用いて，Fig. 2.6 のよに直立，右脚挙 上, 頝部屈曲を子じもマルチボディモデルの初期姿勢とし, 転落挙動の違いの比較シミュレーションを MADYMO ver6.3(TNO-Automotive)により行った. その結果, Fig. 2.7 の ように姿勢は転落挙動に影響することがわかり，姿勢を考慮 したシミュレーションを行う必要があるといえる。

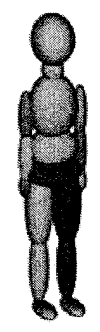

Fig. 2.1 Body shape of Child multi-body model

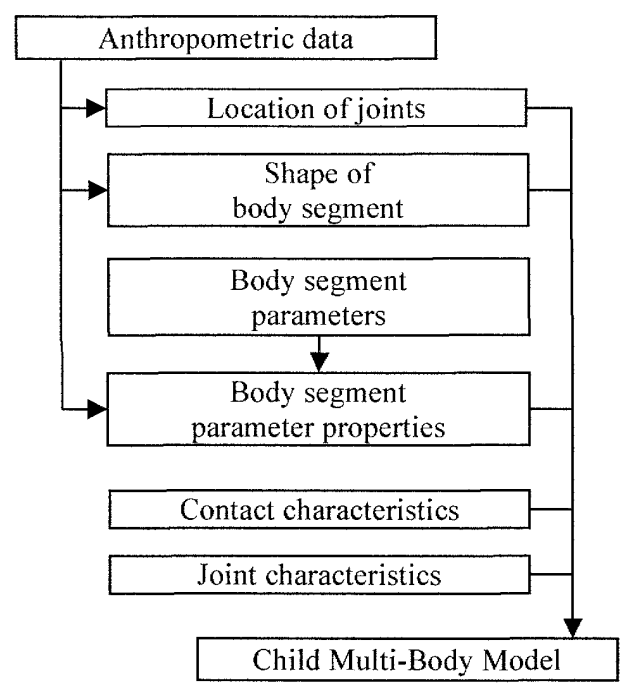

Fig. 2.2 Flow of constructing child model

Table 2.1 Dimensions of the body

\begin{tabular}{cccc}
\hline ID & Dimension & ID & Dimension \\
\hline $\mathrm{D}_{0}$ & Weight & $\mathrm{D}_{20}$ & Upper limb length \\
$\mathrm{D}_{1}$ & Stature & $\mathrm{D}_{21}$ & Forearm circumference \\
$\mathrm{D}_{2}$ & Head length & $\mathrm{D}_{22}$ & Forearm breadth \\
$\mathrm{D}_{3}$ & Head breadth & $\mathrm{D}_{23}$ & Radial-stylion length \\
$\mathrm{D}_{4}$ & Head height & $\mathrm{D}_{24}$ & Hand length \\
$\mathrm{D}_{5}$ & Tragion to back of & $\mathrm{D}_{25}$ & Hand breadth \\
$\mathrm{D}_{6}$ & Tragion to top of head & $\mathrm{D}_{26}$ & Index finger depth \\
$\mathrm{D}_{7}$ & Neck circumference & $\mathrm{D}_{27}$ & Wrist circumference \\
$\mathrm{D}_{8}$ & Lateral neck breadth & $\mathrm{D}_{28}$ & Thigh circumference \\
$\mathrm{D}_{9}$ & Biacromial breadth & $\mathrm{D}_{29}$ & Trochanteric height \\
$\mathrm{D}_{10}$ & Chest depth & $\mathrm{D}_{30}$ & Calf circumference \\
$\mathrm{D}_{11}$ & Chest breadth & $\mathrm{D}_{31}$ & Tibiale height \\
$\mathrm{D}_{12}$ & Suprasternale height & $\mathrm{D}_{32}$ & Foot length \\
$\mathrm{D}_{13}$ & Abdominal depth & $\mathrm{D}_{33}$ & Foot breadth \\
$\mathrm{D}_{14}$ & Waist breadth & $\mathrm{D}_{34}$ & Lateral malleolus height \\
$\mathrm{D}_{15}$ & Hip circumference & $\mathrm{D}_{35}$ & Ankle circumference \\
$\mathrm{D}_{16}$ & Hip breadth & $\mathrm{D}_{36}$ & Sitting height \\
$\mathrm{D}_{17}$ & Iliocristal height & $\mathrm{D}_{37}$ & Elbow height, sitting \\
$\mathrm{D}_{18}$ & Crotch height & $\mathrm{D}_{38}$ & Shoulder-elbow length \\
$\mathrm{D}_{19}$ & Upper arm & $\mathrm{D}_{39}$ & Middle finger length, \\
\hline & circumference & & dorsal \\
\hline
\end{tabular}




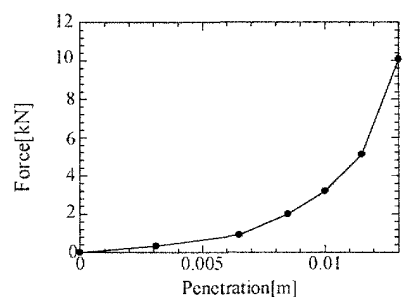

Fig. 2.3 Forearm contact characteristic

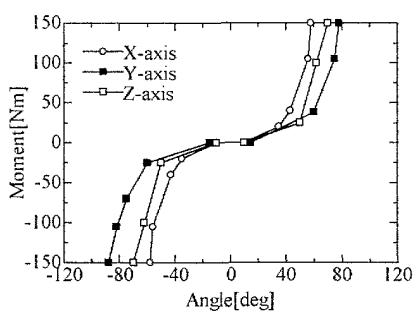

Fig. 2.4 Neck joint characteristics

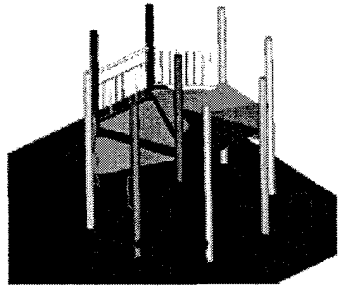

Fig. 2.5 Spiral stairs model

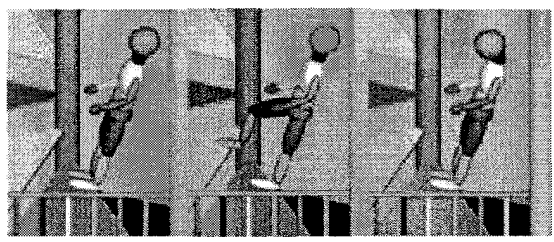

Fig. 2.6 Initial posture

(Upright(Left),Leg flexed(Center),Head bent down(Right))

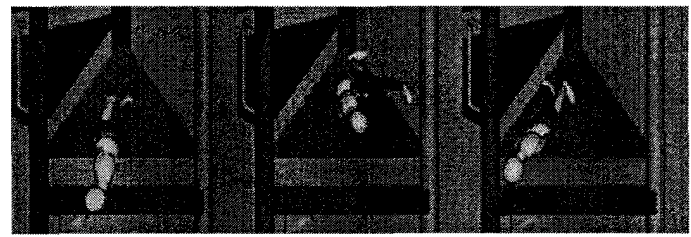

Fig. 2.7 Downfall behavior

( Upright(Left),Leg flexed(Center),Head bent down(Right) )

\section{3. 逆問題的手法による転落事故の状況推定法の構築}

状況推定法の構築手順として,まず事故の結果情報を基に 目的関数を作成した。これには文献 ${ }^{(6)}$ を参考とし, 頭部・胸 部・腹部体節について,シミュレーションから計算された転 落位置と目標となる実事故における転落位置との相対距離 の 2 乗和とした. 次に応答曲面法(7)によパラメータスタデ イの結果を基に入力変数と目的関数との関係を数式化した. 最後に, GAにより目的関数を最適化する入力变数を探索的 に求めた。
本推定法の妥当性老検証するために，一例の転落シミュレ ーションを例題とし, 提案する状況推定法によりその初期状 態を推測することとした。まず, 単純な転落举動として螺旋 階段 1 段目からの転落を考えた. Fig. 3.2〜3.3に示すように, 初期位置 12 籄所, 転落方向 4 方向として, シミュレーショ ンを 48 通り行い，その結果から 3 次多項式により近似され た応答曲面を算出し，それを GAにより最適化することによ り初期状態を推定した。なお, GAの計算条件は,世代数 25 ,

個体数 10 ，さらに1点交叉学行うこととした。

推定された転落挙動は例題として用意したシミュレーシ ヨン結果とよく類似した. 初期位置, 転落方向および転落位 置の目標值との誤差を Table3.1 に，各体節の最大加速度を Table3.2 に示寸. 以上より, 構築した状沉推定法の方法論は 妥当であると考えられる。また，応答曲面法により，GAの みで最適化を行った場合の5分の1にまで計算量を低減でき た.

次に, 複雑な接触を伴う転落挙動として, 螺旋階段 3 段目 からの転落について検討した.目的関数の值がより複雑に変 化すると考えられたため,パラメータスタディの粒度を分け た. Fig. 3.5〜3.6に示すように，まず初期位置 12 箇所，転 落方向 4 方向として 1 回目の大域的なパラメータスタディを 行った.この結果を基に入力変数の変動範囲を狭め, 水準間 隔を半分にし，初期位置 25 䇢所，転落方向 5 方向としてパ ラメータスタディを実施しっこの結果から応答曲面を作成し GAにより最適化した。こうして推定された転倒挙動は，頭 部と螺旋階段 1 段目との衝突形態が例題のものと異なった ものの，定性的に類似した転落挙動となった。初期位置，転 落方向および転落位置の目標值との誤差をTable 3.3 に, 各体 節の最大加速度を Table3.4 に示す．以上より，複雑な形状の 外部環境との接触では推定精度が低下寸ることがわかった. 精度向上にはモデルの外形状・接触特性などに, より詳細デ 一タが必要と考えられる。

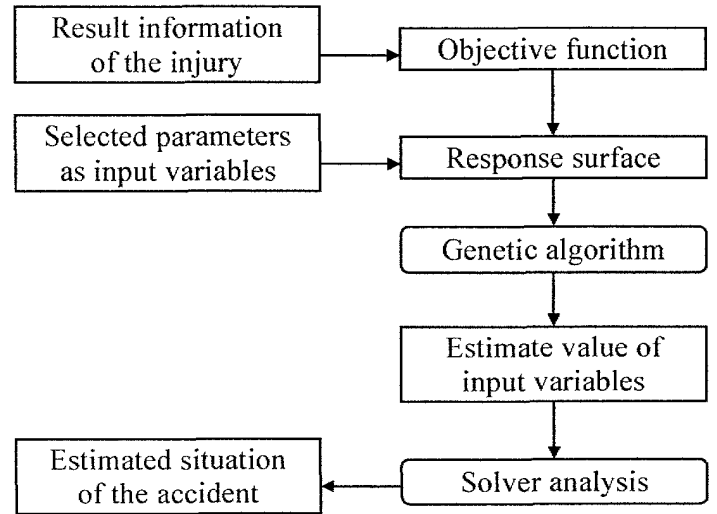

Fig. 3.1 Flow of construction of the estimating method 


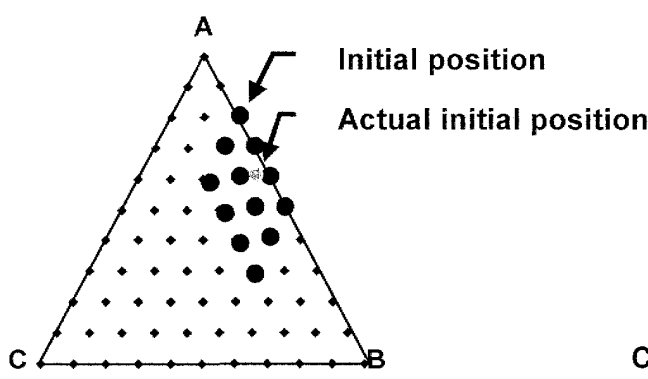

Fig. 3.2 Initial position of child multi-body model
Actual fall direction

Child multi-body model

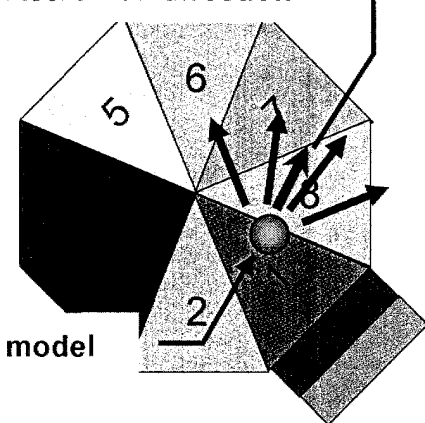

Fig. 3.3 Fall direction of child multi-body model

Table 3.1 Error of initial position, fall direction, and fall position Initial position Fall direction Fall point of body segments [m]

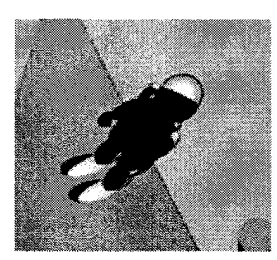

(a) Initial position

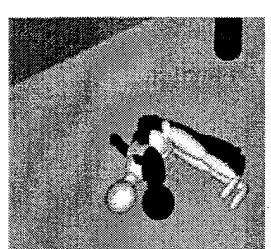

(b) Fall position

Fig. 3.4 Overlaid view of child models

( The estimated fall(blue), The actual(white) )

\begin{tabular}{ccccc}
{$[\mathrm{m}]$} & {$[\mathrm{deg}]$} & Head & Torso & Abdomen \\
\hline 0.022 & 4.6 & 0.195 & 0.043 & 0.058 \\
\hline
\end{tabular}

Table 3.2 Maximum linear acceleration at each body segment

\begin{tabular}{lccc}
\hline \multirow{2}{*}{ Downfall behavior } & \multicolumn{3}{c}{ Acceleration at body segment $\left[\mathrm{m} / \mathrm{s}^{2}\right]$} \\
& Head & Torso & Abdomen \\
\hline Estimated & 2015 & 669 & 652 \\
Actual & 2285 & 648 & 599 \\
\hline
\end{tabular}

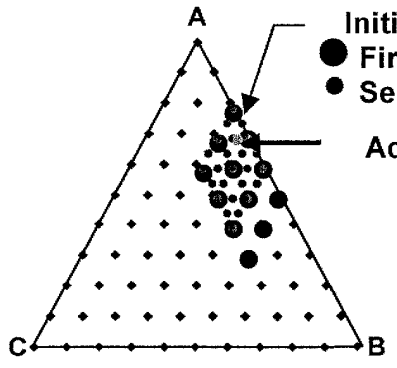

Fig. 3.5 Initial position of child multi-body mode

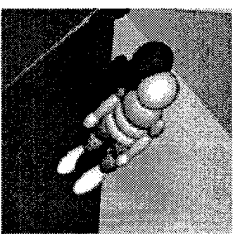

(a) Initial position

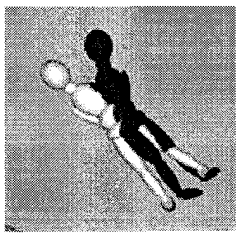

(b) Fall position
Fig. 3.7 Overlaid view of child models ( The estimated fall(blue), The actual(white))
Child multi-body model

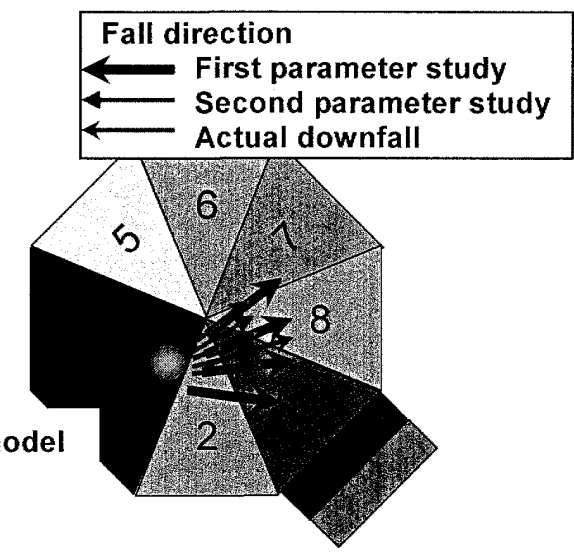

Fig. 3.6 Fall direction of child multi-body model

Table 3.3 Error of initial position, fall direction, and fall position

\begin{tabular}{ccccc}
\hline $\begin{array}{c}\text { Initial position } \\
{[\mathrm{m}]}\end{array}$ & Fall direction & \multicolumn{3}{c}{ Fall point of body segments [m] } \\
\hline $\mathrm{deg}]$ & Head & Torso & Abdomen \\
\hline 0.088 & 4.9 & 0.287 & 0.136 & 0.050 \\
\hline
\end{tabular}

Table 3.4 Maximum linear acceleration at each body segment

\begin{tabular}{lccc}
\hline \multirow{2}{*}{ Downfall behavior } & \multicolumn{3}{c}{ Acceleration at body segment $\left[\mathrm{m} / \mathrm{s}^{2}\right]$} \\
& Head & Torso & Abdomen \\
\hline Estimated & 1913 & 574 & 494 \\
Actual & 2450 & 608 & 507 \\
\hline
\end{tabular}




\section{4. 提案手法の実事故例への適用}

構築した状況推定法を実事故に適用しその推定精度を検 証した，事故情報は以下の通りである．5歳女巟が本遊具の 螺旋階段中央の柱に寄りかかっていたところ,バランスを崩 し地面まで転落し, その際階段のどこが背中が衝突し腎臓 を損傷したが，頭部に受傷はなかったということである。こ のように笑事故デー夕は, 事故状沉を詳細に把握するための 情報が久損していることが多い。

そこで,この情報を基に状況推定法から転落挙動を推定し た。まず，Fig. 4.1 に示すように，産総研の行った害験から シミュレーションにおける目標転落位置を定義した。次に， Fig. 4.2 のうに螺旋階段 3 段目において中央の柱に背中あ るいは右肩で寄りかかった姿勢を 4 種類定義し，各姿勢につ いて本研究で対案する状況推定法を適用した．Fig. 4.3 のよ うに，柱を中とした円周上において，初期位置 5 籄所，転 落方向 5 方向とし，4 姿勢で合計 100 のシミュレーションを 行った。本シミュレーション結果より応答曲面を作成し, GAにより最適化した．推定された転落挙動のうち，Fig. 4.4 に示した姿勢(a)では，螺旋階段 1 段目のへりと子どもモデ ルの左背面が衝突した。こは人体では腎臟に近い部位であ る.さらに，頭部傷害指標值(HIC)を計算したところ，頭部 の耐性限界值の 1000 を下回る 211 であり，重篤な頭部外傷 の発生リスクは小さかったと推定された。これらは実事故の 子どもの受傷状況とよく合致しており, 本推定法による実事 故状況の推定可能性が示晙された。
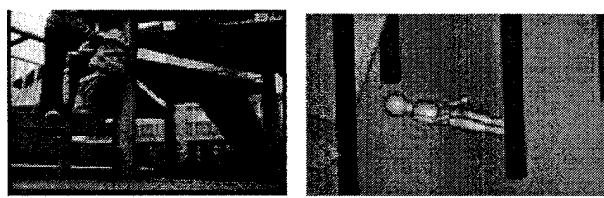

Fig. 4.1 Downfall Experiment(left) and fall position in simulation(right)

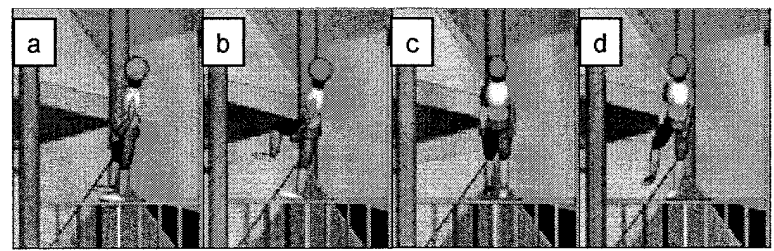

Fig. 4.2 Initial posture of child model

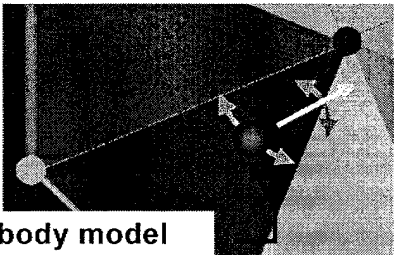

Child multi-body model

Fig. 4.3 Initial position and downfall direction of child multi-body mode

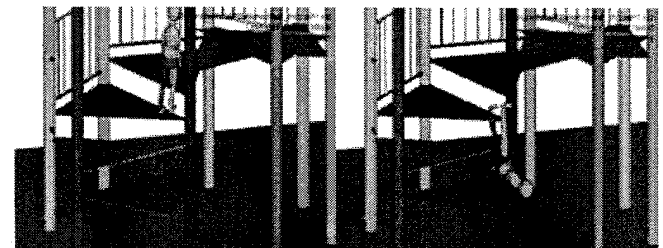

Fig. 4.4 Estimated downfall behavior of posture(a) ( Initial position(Left),Contact between back and stair edge(Right) )

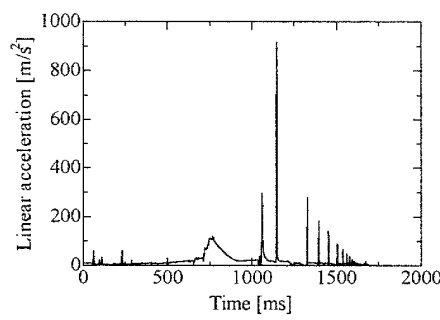

(a) Head

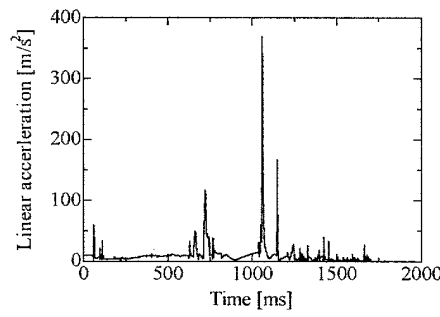

(b) Torso

Fig. 4.5 Linear acceleration (Downfall behavior of posture(a))

\section{5. 結論}

本研究では,子どもマルチボディモデルと螺旋階段モデル を用いた転落事故シミュレーションを利用して,事故データ に久損している事故発生過程の状況を推定する手法を提案 した. 本手法は, 応答曲面法と $\mathrm{GA}$ 老組み合わせ少ない計算 コストで事故の結果情報から事故状況を逆問題的に推定す る乎法である。本手法を，実事故例に適用した結果，事故状 況を推定できる可能性があることを示せた。

\section{6. 参考文献}

(1). 厚生労働省，人口動態統計年報主要統計表（最新デ 一夕, 年次推移), (2005)

(2). 東京都消防庁，子どもの事故予防対策検討委員会報 告書, 2006

(3). 渡辺ら，子どもマルチボディモデルの構築と遊環境 の危険度可視化法に関する研究，ジョイントシンポ ジウム, 2006

（4). 横井孝志，渋川㑆二，阿江通良，日本人幼少年の身 体部分係数，体育学研究 $31 ，(1986) ， 53-66$

(5). J.K.Yang Development and validation of a human-body mathematical model for simulation of car-pedestrian collisions, IRCOBI, (1997)，133-149

(6). 伊藤ら，子供歩行者人体 $\mathrm{FE}$ モデルの検証，自動車技 術会, 2007

(7). 轟章, 応答曲面法,

http://florida.mes.titech.ac.jp/responsesurface.pdf 